\title{
A Proposal of Logistic Services Innovation Strategy for a Mining Company ${ }^{a}$
}

\author{
Felisa Córdova', Claudia Durán, ${ }^{2}$ Juan Sepúlveda ${ }^{3}$,Alfredo Fernández ${ }^{4}$, Mauricio Rojas ${ }^{5}$
}

\begin{abstract}
A logistic service innovation strategy for a mining company and their key suppliers is presented, using the win-win concept with the objective of improve its position, policies, strategic objectives and relationships between companies. The strategy allows increasing the business profitability, to diminish the operational costs and the times of negotiation and learning. The chain value of the productive process is analyzed and also the business strategies of each company in order to identify the key factors involved in the strategic alliance. Contracts negotiation between the company and its suppliers is examined by SWOT analysis, Pareto's ABC tool and expert knowledge of the process. The strategy is applied to a mining company and its key suppliers working in the modality of strategic long term alliances.
\end{abstract}

Keywords: Logistics; services; innovation; mining; strategy; win-win concept; suppliers; alliances; negotiation; learning.

${ }^{a}$ This work was supported by the University of Santiago of Chile, Project 0609I7CG DICYT- USACH.

1,2,3 Departamento de Ingeniería Industrial , Universidad de Santiago de Chile, 3769 Ecuador, Santiago, Chile, P.O Box 10233, 56-27I8420I, felisa.cordova@usach.cl,claudia.duran@usach.cl,juan.sepulveda@usach.cl

4,5 Superintendencia de Abastecimiento, Compañía Minera Los Pelambres, 4249 Colo Colo, La Serena, Chile, 44-53I 96,

alfernandez@pelambres.cl,marojas@pelambres.cl 


\section{Introduction}

For large companies globalization has generated new markets and new competitive forces. The constant concern to reduce costs, shorten delivery times (lead times), and focus to the core business has led companies to change their supply chain management strategies. Large manufacturing companies buy today a significant percentage of goods and services from other companies, in some cases spend more than half of their income in this way.

The copper industry has experienced over the past two years an increase in the prices of its products (commodities), mainly due to increased demand generated by emerging economies like China and India. This rise in the prices, reflected in oil and steel, has been accompanied by a shortage of some inputs, such as tires used in mining equipment or milling balls. The fact of not having the production equipment in time, rising prices and shortage of inputs has generated great losses to the mining companies. In particular, the delivery times of mining equipment have been increased to more than the double, in some cases. In this context, the companies seek to form strategic alliances and produce production linkages with other firms, including purchasing, distribution and sales, offer them an avenue through which it can address its objectives. These relationships allow reducing costs while increasing specialization and flexibility.

\section{Literature review}

The traditional way to compete in the mining industry has been through the sustainable profitability of their assets due to the sale of commodities. This has led to opposing supplier's and company's interests in the past. However, the mining leaders, who want to improve their performance and competitiveness standards, are aware that their environment can help them meet their goals. Therefore, looking forward and backward in their value chain, companies may find valuable opportunities to enhance their growth strategies (Harrison et al., 2000, Wong et al., 2005).

Leading companies today are using strategic alliances to develop competitive advantages in quality, innovation, and cost; focused on developing strategic partnerships with their suppliers. Some authors refer to them as "corporate marriages" (Demers et al, 2003) others as "collaboration to compete" (Slowinski et al, 2006). Thus, formed coalitions are formal long-term partnerships between companies that unite some aspects of their activities, but not getting to fusing together. They include joint-ventures, agreements on exploitation licenses, on bids, production and marketing, as well as other kind of agreements (Lo \& Yeung, 2003, Mayer \& Teece, 2008, Porter \& Fuller, 1986).

A Strategic Alliance is a work network formed by institutions or groups of partners who aspire to achieve certain goals with mutual benefits (Grant \& Baden-Fuller, 2004). Other authors define the alliances as cooperative agreements between two or more firms to improve their competitive position and its performance by sharing their resources (Ireland et al., 2002). Strategic Alliances are also defined as associations between institutions or companies, which are grouped to develop joint activities in order to achieve a particular goal, which will benefit all its members (Harrison et al., 2000, Mc. Cutcheon \& Stuart, 2000, Yang et al., 2008). Some authors are focused in facilitating a strategic, tactic and operational interface and collaboration among designer, buyer, and supplier (Dowlatshahi, 2000, Kaplan \& Norton, 2006). Other authors create a "relationship architecture" emphasizing the aspects of just-in-time that relates to linking with suppliers and customers (Narasimhan \& Nair, 2005) or suggest that the strategic factors come from the supplier's management system itself (Shen \& Yu, 2009).

According to these definitions and the experience of the mining industry in Chile, one can say that the philosophy of the strategic alliances is the achievement of a common purpose through the concerted support of all members of the association in an organized manner, providing benefits to its participants in a fair and equitable way. In this context, this work attempts to show how a mining company, by boosting the creation of strategic alliances with its key suppliers, seeking expertise in third parties and changing the way of doing business' paradigm, has been able to confront the main problems that the mining industry is experiencing today. This has helped to improve the profitability of the parties and ensure the company's business continuity. 


\section{Method}

\section{Identification of the current problem}

By making an analysis of the relationships between companies and their suppliers, the business environment and the domestic problems of mining companies, four major difficulties were distinguished.

Misalignment between the company and the contractor: The contractor's business horizon is short or medium term, while the mining company's is long term. The alignment of the time for business would allow the contractor to amortize the capital cost and the mining company to reduce costs and stabilize its processes. Nowadays, there is a divergence of interests between the parties, since the contractor does its business according to its traditional pattern, which is not always the best deal for the mining company. Such is the case of earthmoving companies, who charge for the amount of hours their machines, operate and not by the quantity of earth moved. Another example is the MARC contracts that charge by machinery availability and operational hours and not by tons of rock loaded and / or transported. Suppliers of drilling steel or tires, for its part, bill for amount of sold items and not by their length or performance.

There is a high change cost, with every new contract, both in learning the culture of the mining company, as in the trusts in trade and labour relations, in the internalization of safety, quality and risk practices.

Market Contingencies and Suppliers Industries:

The high copper prices force the company to produce the largest amount of copper in the shortest possible time. In interviews conducted with executives of the mining company in study feels that there are strong oligopolies in key services and supplies, very few suppliers and / or contractors for some critical processes. Inputs' prices are rising and are scarce.

Changes in employment laws:

These changes force to ensure a climate of excellence in labour relations, incorporating the workers in the benefits of the business' profits.
Rising costs in the company:

This is due to the growth of mining operations, mining profiles and the new exploitation stages, which increase the distances of minerals transportation. Moreover, in many cases, the aging of the mine brings with it a growing decline in the purity of the ore (base ore) and changes in its litho logy, making the mineral harder, which hits in a higher consumption of steel coating for crushers and mills, along with increased energy consumption. The aging of the equipment, leads to higher maintenance costs, purchase of spare parts and low availability.

\section{Methodology}

The developed methodology has enabled: the situational diagnosis of the procurement of goods and services process; the analysis of critical processes in the context of the value chain; the identification of the main critic suppliers; and the design of the business strategy to be developed for each process.

The methodology consists of the following steps:

Step I: graphing the production process. To graph the production process and identify the value chain, making a map of the main threads.

Step 2: identifying the key processes. Identification of the key processes through a Pareto's $A B C$ analysis based on the annual cost of the contracts, criticality from the point of view of the processes and the RSE and market share of the contractors. Then, the analysis of the current status of these contracts or businesses is accomplished.

Step 3: identifying mutual benefits. Identify levers of mutual benefit to align interests of the parties.

Step 4: economic evaluation. It is necessary to provide an economic evaluation of hiring scenarios.

Step 5: SWOT Analysis. SWOT Analysis is necessary to choose a scenario to develop recommendation of the Business Strategy of the chosen option.

Step 6: Business development. Finally a business development is taken in account. 


\section{Implementation of the methodology in the mining company}

\section{Strategic Guidelines}

Based on the challenges posed by the company's shareholders, the addressing of the top management and the identification of critical success factors for the mining company, it raises the following mission: "To continuously increase the value of the company over its opportunity cost through a business' excellence management, its processes and projects within a framework of sustainable development." Strategic management of the company (Kaplan \& Norton, 2006), in Supply and Contracts units, materializes in the development of concrete plans to generate business with its suppliers and contractors that allow the meeting of the management's guidelines.

\section{Identification of the Productive Processes and the Value Chain}

The processes' structure that allows the company's the obtaining and marketing of their products is a business model that is made up from production and delivery processes, operational support processes and from services, which are somewhat administrative support processes. The company at its inception established an integrated but traditional relationship with the suppliers, which according to the evaluations' analysis resulted in the formation of Strategic Alliances, which are better suited to the processes, including them in the production structure of the mining company and integrating them to the business. The contracts with important suppliers are long-term and performance agreements are signed with incentives on the outcome of the management.

\section{Identification of Key Processes According to the cost}

In order to identify those key and strategic suppliers, a Pareto's ABC analysis was made to main company's contracts, whose spending exceeds one million dollars per year. The results are shown in Figure I. On the chart, the Strategic segment was determined, consisting of major contracts which represent $80 \%$ of total spending and have great impact on production, with few market participants. According to the result of the Pareto analysis, strategic services or inputs are: power supply, fuel supply, mine transportation service, milling ball supply, mine auxiliary equipment service, loading equipment maintenance service, drilling MARC service and drilling machines, explosives supply, plant maintenance and supply of giant tires.

\section{Main Services' and Contracts' Current Situation Analysis}

Power Supply: it is performed by a large company in the Chilean market. The payment is for power and energy. The mining has pushed a policy of energy efficiency that is based on controlling demand at peak hour and power co-generation, through an own backup electricity generating central of $5 \mathrm{MW}$. These two initiatives allow to be prepared to face possible crisis in electricity supply. Other power generation alternatives (wind and water) are being explored. Figure I shows the Bubble Chart for Strategic Allies Identification. 


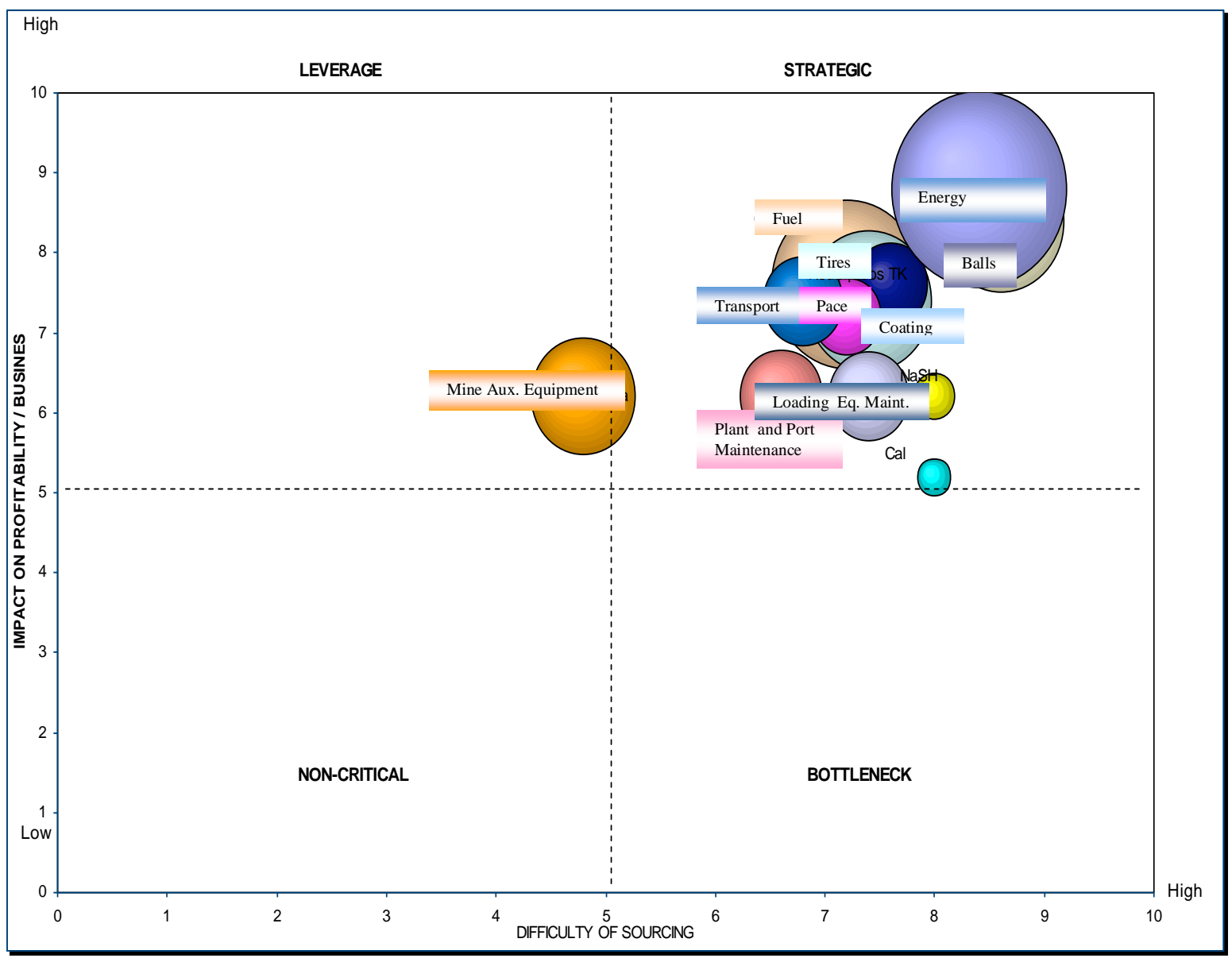

Figure I. Bubble Chart for Strategic Allies Identification. Data from Los Pelambres Mining Company (2008)

Fuel Supply: the Service is conducted by one of the three major fuels and lubricants providers. It is paid per litre consumed as the market price plus freight to work place. It also considers the service of maintaining the facilities (pumps) and internal distribution. The company, together with its strategic partner for the supply of explosives has developed a reuse of lubricating oil project draft, with the aim of reducing the consumption of diesel in the generation of explosives. Significant savings in fuel consumption have been gained, reducing hazardous waste generation. These actions and other actions carried out, aim at controlling the rising price of fuel and an environmental performance of excellence.

Mine Transportation Service measured in Cost per ton (CPT): this service comes from a Strategic Alliance with two of the key members in the mining trucks global market. It consists in a mine transport service with a number of trucks that depends on the production schedule, which varies over time, where a "carrying capacity" is established and guaranteed. The main value lever of this contract is to pay for the tonnes actually carried. The contract is considered a revision of contract terms every two years by the completion of a Balanced Scorecard and benchmarking with other domestic and foreign mining companies, in order to rectify and integrate new technologies.

Provision of milling balls: it is done by the main national supplier. Payment is by tons consumed, according to the balls diameter. The material is on consignment, with treemonthly adjustments according to steel indicators. Payment for mill performance is yet to be explored. The possibility of buying milling balls in conjunction with another mining group with alternative suppliers (Peru and China) is being explored.

Mine Auxiliary Equipment Service: it consists of a rent contract of earthmoving equipment such as bulldozers, tank trucks, middle chargers, and so on. The most relevant 
activities relate to maintenance of loading platforms, irrigation and maintenance of roads, clearing snow and earth movement in general. It is paid for operation hours. This recruitment model is a clear example of divergent interests, because on one hand the vendor wants to sell the maximum number of hours and the buyer to perform its task using a minimum number of hours. Figure 2 shows Expenses Production Relationship for the Company. It is advisable to seek a payment option other than the hourly machine fee, for one modality that is associated with the service and expected profit.
Mine Loading Service: it consists of a Maintenance and Repair Contract (MARC) of loadings equipments with Minepro. The contract gives the company a percentage of availability of the equipment and the fleet as a whole, and it pays a fee according to each equipment operational hours used. The performance of the equipment and mine production are entirely dependent on the company. It would be advisable to seek a payment option different from the MARC fare, with some form associated with the benefit that such service leads in the production process. The Pelambres Mine is introducing new loading equipment with Komatsu Company, in the contractual form of payment for loaded tons. This action allows generating a commercial competition among suppliers and assessing the suitability of the business model.

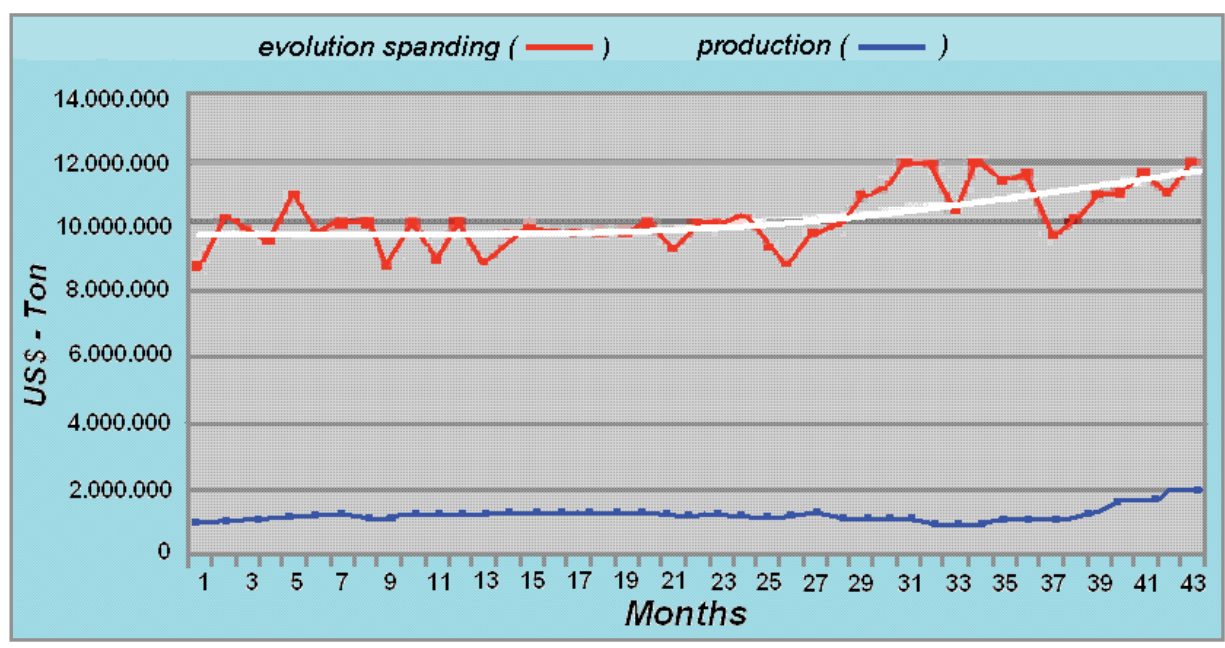

Figure 2. Expenses Production Relationship. Data from Los Pelambres Mining Company (2008)

Drilling Service: there are six contracts, which consider the supplying of drilling steel, drilling equipment leasing and MARC maintenance of own equipment. There is a large amount of contracts associated with the same process, with contractual relationship scopes and modalities with many differences between them. This generates a complex administration, especially in security, operational effectiveness controls, administrative documentation and with little synergy between the different actors. Nor has clauses oriented to appropriate development of the drilling tasks and of service quality, by suppliers. The energy use in crushing and milling and refining the forecast of metallurgical performance in plant is subsequently reduced. Developing partnerships aim to have only one vendor to run a full drilling service (capital, maintenance, operation and steel drill).
Explosives Supply: it develops in a Strategic Alliance with the main explosives supplier in the country. This service is based on the Mine to Mill principle (from mine to plant). The principle of this concept aims to create value in all processes downstream of the blasting. It is paid for grain size achieved by the blasting measured on the ore transporting belt. The grain size is privileged over consumption of explosives.

Maintenance Plant: takes place in a Strategic Alliance with FL Smidth Minerals Chile, and consists of a complete maintenance service of the concentrate copper and molybdenum plants. The main functions are to improve the availability, reliability and total cost of maintenance, ensuring the life and upgrading of equipment and facilities. 
The form of payment commits the contractor to improve the availability of the plant. It is paid per ton of ore processed and for management in terms of availability, unitary cost of maintenance and reliability.

Giants Tires Supply: it is performed in a Strategic Alliance with Michelin, in a service called Ton/Kilometre (TK), which consists in changing the way you manage the tires item, through a payment based on performance of the tires used in the fleet of extraction trucks. A rate is applied depending on the monetary tons / kms. that is produced in a given period. The benefits of this service are: for the company, increased availability of trucks to generate the greatest amount of ore for the plant, and for the contractor, a greater return per tire unit.

\section{Mutual benefit Levers to Align the Interests of the Parties}

To $100 \%$ of service contracts from the mining company have a Performance Agreement, based on a Balanced Scorecard according to the service, which allows to calculate and pay a bonus to employees of contracting companies in order to boost their productivity, maintaining good industrial relations and make them part of the business. The company favours lasting contractual relationships, either through long-term contracts with early departure clauses depending on the outcome of the conventions of performance and benchmarking evaluation, or through contracts with continuous renewal. They are short-term contracts that can be renewed under the same evaluation parameters. These levers allow the mining company to achieve its strategic and operational objectives, to maintain good working relationships, improve its profitability and develop a business in a sustainable manner over time.

\section{Evaluation of Scenarios Recruitment}

The main improvement opportunities identified in the analysis of the services' contractual status are:

- Improve the drilling service, because there are too many contracts and they are not aligned with the objectives of the mining company.

- Improving the contract terms with the provider of loading equipment maintenance service.

- Improve the mine auxiliary equipment service through a competitive bid that incorporates a payment function according to the final result of the mine production.
From the analysis of the current status of main services and contracts related to the so called critics processes, is presented below, an assessment of the possible different drilling service recruitment scenarios and their improvement initiatives.

Analysis of the Process of Drilling Production:

Good suppliers are at disposal, all with proven experience and open to innovation; it is possible to directly link the value of the service with the end product of the mine. There also is knowledge and experiences at disposal that allow establishing a fairly predictable projection of the process' behaviour, which allows significantly lowering the level of risk during negotiations with suppliers.

Therefore, to rephrase the current contractual status has no greater complexities and it's recommended in this case:

- Promote the integration among different service providers, so to have only one contract that by this concept improves the synergies between the parties (more efficiency) while allowing each to focus on giving the service what it knows how to do better.

- Associate the value of service in this single contract to a cost directly linked to the mine end-product, which in this case would be cost per meter drilled.

- Incorporate a recognition and penalty clause by concept of improving the quality and opportunity of performing the drilling tasks, which as noted is of particular importance in the operational results of the processes downstream.

\section{Services Evaluation}

To the drilling service has been executed with various forms of contracts and different suppliers at a time. The options to assess are given below:

- Internalization of the Service.

- Purchase of equipment with MARC maintenance.

- Rental of equipment with MARC maintenance.

- Full Service. This method considers the Supplier includes equipment and its maintenance and operation.

\begin{tabular}{|l|l|}
\hline VAC Options 10\% & Dif. \% \\
\hline Full Service & 0 \\
\hline Rental +MARC & $12.46 \%$ \\
\hline Purchase +MARC & $15.99 \%$ \\
\hline Internalization & $16.20 \%$ \\
\hline
\end{tabular}

Table I. Result of the Services Evaluation. 


\section{SWOT analysis to choose a scenario to develop}

In order to have a much more widespread vision in respect of the advantages and disadvantages of opting for certain activities to develop with the company's own resources or a third's, the SWOT analysis was made.

Strengths:

- Trust relationships accomplished by strategic alliances.

- Cost control (win-win).

- Shared management systems.

- Building shared business vision.

- MPL maturity.

- Risk declaration and cost assumption.

- Centralizing shared services.

Weaknesses:

- High cost of change.

- Absence of an internal maintenance unit.

- Litho logy changes.

- Dependence of companies in short time. Opportunities:

- Flexibility and high technologies update.

- Competitive scenarios management.

- Connecting contract results with business value.

-Evolution from selling equipments to solve business needs.

- Technology transfers.

- Inter-companies knowledge.

Threats:

- High prizes scenarios.

- Labour law.

- Input prices increasing.

- Excessive dependence of headquarter.

From the weaknesses and threats to the scenery of generating a Strategic Alliance with full service, it can be appreciated that the majority of them are controllable and it is possible to transform them into Strengths and Opportunities. Except for variables such as the Labour Law which, by being a decision of the authority, could become a force majeure and the absence of an internal maintenance unit, which would mean an investment in knowledge, it is estimated a learning curve for 2 to 3 years to think in the internalization of the service.

\section{Recommendation of the Business Strategy}

From the results of the VAC for the various options in the economic evaluation, it's verified that the service's value is a crucial background to take the decision over the option that provides greater benefits. In order to achieve greater efficiency in operations, it must be chosen to hire a service which cost is aligned directly with the end product of the mine. This provides a better costs' predictability and creates less administrative and operational difficulties. On the other side, the company cannot tackle the tasks of equipment maintaining. This means that in the short term is not feasible to internalize activities.

In the case of drilling equipment, it is recommended to promote the formation of a work team that includes maintainers, operators and steel suppliers, which together can deliver a complete service. The leadership of this team will be taken by the company or group of companies that meet the best conditions to manage the service under a payment mode per meter drilled.

The long-term alliance should be established through a competitive bidding, which allows having a contract of the following characteristics: it must be embedded in the Policies, Values and Strategic Objectives of the mining company, ensure the best VAN for both parties; periodically assess its operational efficiency, make the payment function more flexible; generate incentives for performance, both of the contracted service as the of the mining company's business, encourage technological development and personnel training. A process of vendors sensitizing must also be initiated, once they have selected potential partners with development potential in this new style of business.

\section{Results}

The developed Strategic Alliances are long-term, of mutual benefit, with common goals and based on trustworthy relationships, according to the Strategic Directions and Values. The contracts of the mine transport service have a horizon of 10 years and with output options, enabling to project a known expenditure level, to increase the return on the assets of the company (ROCE) and enables the convergence of interest between the parties. On the other hand, they permit to count with secure access to critical inputs supply, against the market eventualities (TK tire service case).

The implementation of compensation mechanisms based on performance, targeted directly toward the contractors' 
employees, makes suppliers prefer the company and powers, through motivation, compliance with the specific objectives of each contract.

From the standpoint of cost increases due to internal factors, the development of strategic alliances creates opportunities for innovation and encourages partners to develop mechanisms to improve their productivity and performance. Such is the case of the Plant Maintenance
Service, where in spite of the equipment's aging; the availability of these has been growing over time and its overall cost of maintenance lowering.

The developed Business Model could mean savings opportunities of up to $4.2 \%$ in the operation's cost of service, as pointed out a study in 2008 to the Sourcing Strategy of Los Pelambres Mine in the mining industry. This situation is presented in Figures 3 and 4.

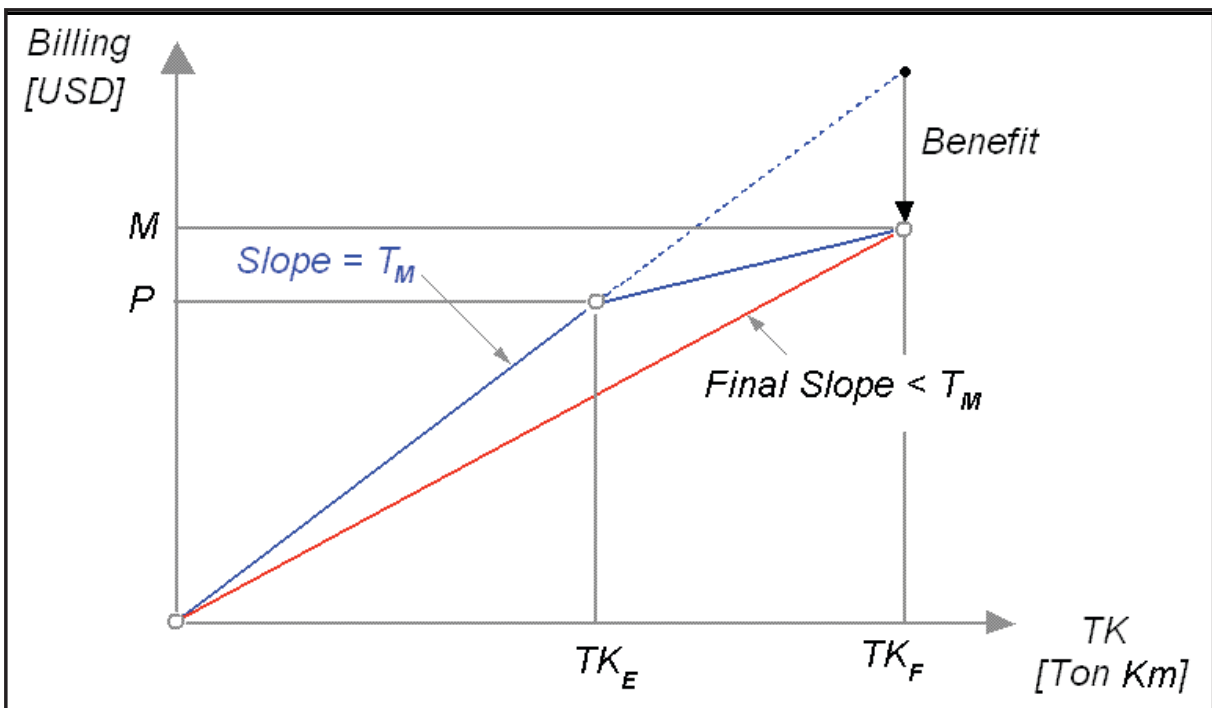

Figure 3: Los Pelambres Profits, Data from TK Project's Benefits Model, Boston Consulting Group (2008)

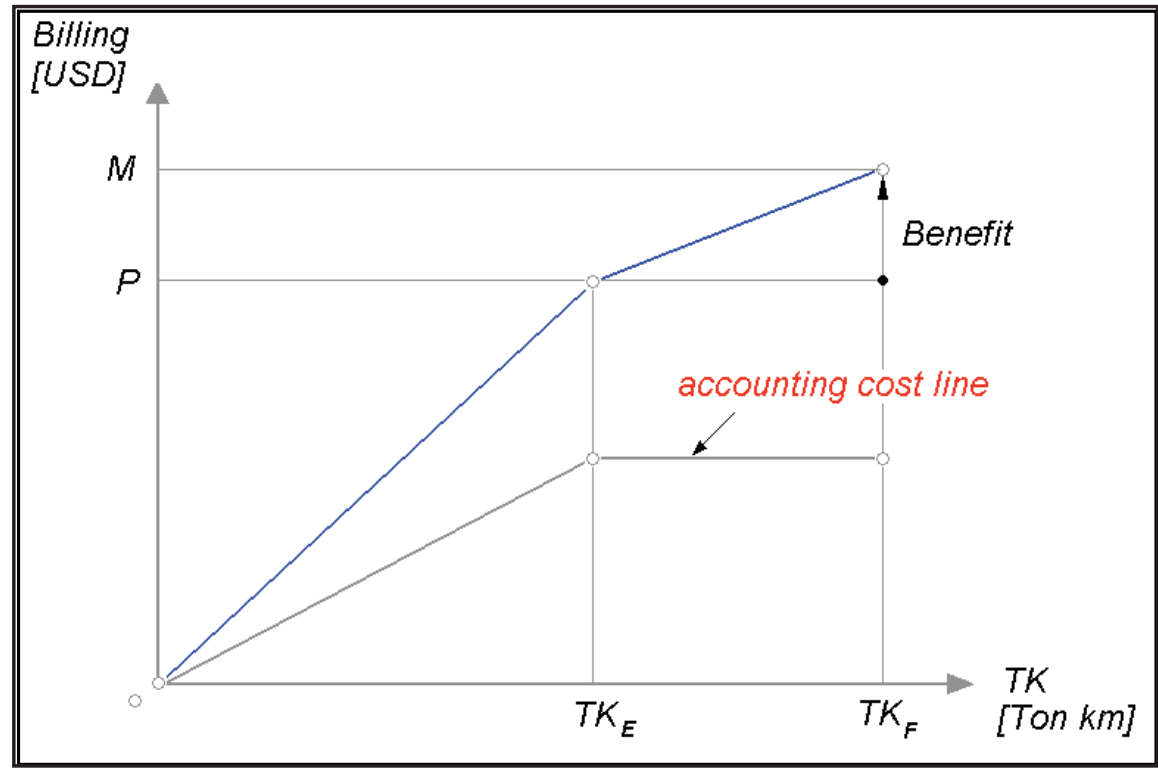

Figure 4: Michelin’s Profits, Data from TK Project's Benefits Model, Boston Consulting Group (2008) 
The win-win concept which is referred to in the Alliances, is possible to appreciate it clearly in already implemented services, such as the TK contract, where the marginal benefit per unit of output is shared by members of the Alliance; the blasting service by fractured rock, which positively impacts on the rest of the production chain, generating a higher return on the global extraction agenda (downstream processes).

\section{Discussion}

The methodology presented in this study is not designed to replace the traditional recruitment or acquisition models; it rather opens a new vision of business doing between partners involved in the productivity of the mining industry. The study case of the mining company allowed the making of a full diagnosis of the contractual situation and a proposal for a business strategy for those critical processes of the value chain, according to a methodology proposed.

The developing of new ways of doing business with suppliers and contractors has prompted them to create spaces of continuous improvement and development of new technologies, tools and / or applications that enable them to achieve a better performance and thus maximize the profitability of their business.

In the Strategic Alliances' scheme, the parties' interests are aligned in the same direction, since results are obtained and I or products returns agreed between the partners. This methodology may be viewed as a Practical Guide for analysis to be applied by those who wish to innovate in the way of realizing strategic alliances with suppliers in the industry.

\section{References}

DEMERS, Ch., Giroux, N., Chreim S. (2003). Merger and acquisition announcements as corporate wedding narratives. Journal of Organizational Change Management, 16 (2), 223-242.

DOWLATSHAHI, S. (2000). Designer-buyer-supplier interface: Theory versus practice. International Journal of Production Economics, 63 (2), III-I30.

HARRISON, J.S., Hitt, M.A., Hoskisson, R.E., Ireland, R.D. (2000). Resource complementarities in business Combinations: extending the logic to organizational alliances. Journal of Management, 27, 679-690.

GRANT, R. M., Baden-Fuller, C. (2004). A knowledge assessing theory of strategic alliances. Journal of Management Studies, 4I(I), 6I-85.

IRELAND, R. D., Hitt, M. A., Vaidyanath, D. (2002). Alliance management as a source of competitive advantage. Journal of Management, 28 (3), 4I3-446.

KAPLAN, R., Norton, D. (2006). Alignment: Using the Balanced Scorecard to Create Corporate Synergies. Harvard Business School Press, Boston, MA, USA.

YANG, J., Wang, J., Wong, C., Lai, K. (2008). Relational stability and alliance performance in supply chain. Omega, 36(4), 600-608,

LO V., Yeung, A. (2003). Practical framework for strategic alliance in Pearl River Delta manufacturing supply chain: A total quality approach. International Journal of Production Economics, 87(3), 23I-240.

MAYER, K., Teece, D. (2008). Unpacking strategic alliances: The structure and purpose of alliance versus supplier relationships. Journal of Economic Behaviour \& Organization, 66(I), 106-I27.

MC. CUTCHEON D., Stuart F.I. (2000). Issues in the choice of supplier alliance partners. Journal of Operations Management, I8(3), 279-30I. 
NARASIMHAN, S., Nair, A. (2005). The antecedent role of quality, information sharing and supply chain proximity on strategic alliance formation and performance. International Journal of Production Economics, 96(3), 30I-313.

PORTER, M.E., Fuller, M.B. (1986). Coalitions and Global Strategies, In Porter, M.E. (Ed.): Competition in Global Industries. Harvard Business School Press, Cambridge, USA.

SHEN, Ch., Yu, K. (2009). Enhancing the efficacy of supplier selection decision-making on the initial stage of new product development: A hybrid fuzzy approach considering the strategic and operational factors simultaneously. Expert Systems with Applications, 36(8), II27I-II 28.

SLOWINSKI, G., Sagal, M. (2006). Allocating Patent Rights in Collaborative Research Agreements. ResearchTechnology Management, 49(I), 5I-59.

WONG A., Tjosvoldt, D., Zhang, P. (2005). Developing relationships in strategic alliances: Commitment to quality and cooperative interdependence. Industrial Marketing Management 34(7), 722-73I. 